\title{
Apparent selective bile acid malabsorption as a consequence of ileal exclusion: effects on bile acid, cholesterol, and lipoprotein metabolism
}

\author{
J-E Åkerlund, I Björkhem, B Angelin, L Liljeqvist, K Einarsson
}

\begin{abstract}
A new model has been developed to characterise the effect of a standardised ileal exclusion on bile acid, cholesterol, and lipoprotein metabolism in humans. Twelve patients treated by colectomy and ileostomy for ulcerative colitis were studied on two occasions: firstly with a conventional ileostomy and then three months afterwards with an ileal pouch operation with an ileoanal anastomosis and a protective loop ileostomy, excluding on average $95 \mathrm{~cm}$ of the distal ileum. The ileostomy contents were collected during 96 hours and the excretion of bile acids and cholesterol was determined using gas chromatography-mass spectrometry. Fasting blood and duodenal bile samples were collected on two consecutive days. After the exclusion of the distal ileum, both cholic and chenodeoxycholic acid excretion in the ileostomy effluent increased four to five times without any change in cholesterol excretion. Serum concentrations of lathosterol (a marker of cholesterol biosynthesis) and $7 \alpha$-hydroxycholesterol (a marker for bile acid biosynthesis) were increased several fold. Plasma concentrations of total VLDL triglycerides were also increased whereas the concentrations of total and LDL cholesterol, and apolipoprotein $B$ were decreased. There were no changes in biliary lipid composition or cholesterol saturation of bile. The results show that the exclusion of about $95 \mathrm{~cm}$ of distal ileum causes malabsorption of bile acids but apparently not of cholesterol. The bile acid malabsorption leads to increased synthesis of both bile acids and cholesterol in the liver. It is suggested that bile acids can regulate cholesterol synthesis by a mechanism independent of the effect of bile acids on cholesterol absorption. The enhanced demand for cholesterol also leads to a decrease in plasma LDL cholesterol and apolipoprotein $B$ concentrations. The malabsorption of bile acids did not affect biliary lipid composition or cholesterol saturation, but increased the plasma concentrations of VLDL triglycerides.

(Gut 1994; 35: 1116-1120)
\end{abstract}

The production of bile acids represents an important pathway for cholesterol excretion in humans. ${ }^{1}$ The bile acids are very efficiently reabsorbed from the intestine during their enterohepatic circulation. The absorption occurs mainly by an active carrier mechanism in the distal part of ileum, but also especially for the less polar dihydroxy bile acids by a passive uptake along the whole length of the small intestine. ${ }^{12}$ Ileal dysfunction or resection of the distal ileum therefore causes bile acid malabsorption and an increased faecal loss of bile acids. ${ }^{34}$ Bile acid malabsorption may also affect the micellar solubilisation of cholesterol, thus resulting in impaired cholesterol absorption from the intestine. ${ }^{5} 6$

The malabsorption of bile acids is expected to lead to a compensatory increase in the activity of the rate limiting enzyme in bile acid biosynthesis, the cholesterol $7 \alpha$-hydroxylase. Malabsorption of cholesterol can be expected to lead to a similar increase in the activity of the rate limiting enzyme in cholesterol biosynthesis, the 3-hydroxy-3-methylglutaryl coenzyme A (HMG CoA) reductase. In accordance with this we recently showed that ileum resection leads to increased bile acid biosynthesis as well as increased cholesterol synthesis and increased expression of LDL receptors. ${ }^{7}$

Ileal resection has been reported to be associated with increased incidence of cholelithiasis, and it has been suggested that this is possibly a result of a diminished body pool of bile salts and the secretion of lithogenic bile. ${ }^{89}$ Recently it was shown that in patients with hypercholesterolaemia, who had had a myocardial infarction, ileal bypass surgery reduces the morbidity from coronary heart disease. ${ }^{10}$

In this study we have developed a new model to study the effects of ileal resection. Patients with ileostomy were studied before and three months after exclusion of 95 $(80-120) \mathrm{cm}$ of the distal ileum. We measured the excretion of bile acids and cholesterol through the ileostomy, as well as biliary lipids and bile acid composition in duodenal bile. Serum concentrations of lathosterol - a marker of cholesterol synthesis ${ }^{11} 12$ and $7 \alpha$-hydroxycholesterol - a marker of bile acid synthesis ${ }^{13}$ were determined as well as plasma lipoproteins. The results show that the exclusion of the distal ileum leads to an apparent specific malabsorption of bile acids. This malabsorption was shown to have a stimulatory effect on synthesis of both bile acids and cholesterol. In duodenal bile, biliary lipid and bile acid composition as well as cholesterol saturation were unaffected. 
TABLE I Clinical data of the patients

\begin{tabular}{|c|c|c|c|c|c|}
\hline \multirow[b]{2}{*}{ Patient } & \multirow[b]{2}{*}{ Sex } & \multirow{2}{*}{$\begin{array}{l}\text { Age } \\
(y)\end{array}$} & \multicolumn{2}{|c|}{$\begin{array}{l}\text { Relative body } \\
\text { weight }(\%)^{\star}\end{array}$} & \multirow{2}{*}{$\begin{array}{l}\text { Length of } \\
\text { excluded part } \\
\text { of distal } \\
\text { ileum }(\mathrm{cm})\end{array}$} \\
\hline & & & Before & After & \\
\hline 1 & $\mathbf{M}$ & 34 & 98 & 94 & 80 \\
\hline 2 & M & 56 & 93 & 92 & 95 \\
\hline 3 & $\mathbf{M}$ & 25 & 95 & 94 & 90 \\
\hline 4 & $\mathrm{~F}$ & 20 & 86 & 85 & 80 \\
\hline 5 & $F$ & 41 & 123 & 120 & 120 \\
\hline 6 & $\mathbf{M}$ & 31 & 87 & 86 & 80 \\
\hline 7 & $\mathrm{~F}$ & 38 & 90 & 91 & 80 \\
\hline 8 & M & 51 & 82 & 80 & 90 \\
\hline 9 & $M$ & 22 & 89 & 87 & 95 \\
\hline 10 & $\mathrm{~F}$ & 43 & 89 & 90 & 115 \\
\hline 11 & M & 45 & 85 & 84 & 115 \\
\hline 12 & M & 28 & 86 & 85 & 95 \\
\hline
\end{tabular}

\section{Methods}

\section{MATERIALS}

Deuterium labelled $7 \alpha$-hydroxycholesterol, lathosterol, cholic, and chenodeoxycholic acids were synthesised as described previously.11 1415 Deuterium labelled cholesterol was obtained from Medical isotopes, Inc, Concord, NH, [24-14 C] cholic acid (138 $\mu \mathrm{Ci} / \mathrm{mg})$ and $\left[24-{ }^{14} \mathrm{C}\right]$ chenodeoxycholic acid (138 $\mu \mathrm{Ci} / \mathrm{mg}$ ) were obtained from New England Nuclear Corporation, Boston, MA. 3-Hydroxysteroid dehydrogenase (Sterognost) and cholesterol oxidase (Nyco-test cholesterol) were obtained from Nyegaard A/S, Oslo, Norway.

\section{PATIENTS}

This study consisted of 12 patients, eight men and four women, who had previously had a colectomy and ileostomy because of ulcerative colitis. Their age ranged from 20 to 56 (mean 36) years (Table I). No small bowel resection had been performed. Each patient was studied under two different conditions, firstly with an ordinary ileostomy, and then three months afterwards an ileal pouch operation with an ileoanal anastomosis and a protective loop ileostomy, excluding on an average 95 $(80-120) \mathrm{cm}$ of the distal ileum as measured during the operation (Table I). All patients were in good health during both study periods, judged by history, clinical examination, and routine blood chemistry. No patient was receiving drug treatment.

Informed consent was obtained from each patient. The ethical aspects of the study were approved by the ethical committee of the Karolinska Institute.

\section{EXPERIMENTAL PROCEDURE}

The experimental procedure was identical during the two study periods. All patients stayed in a metabolic unit in hospital and were given a regular ileostomy diet. About $40 \%$ of the energy content was supplied as fat, most of which contained saturated fatty acids. The main part of the carbohydrates, which accounted for $39 \%$ of the energy, was supplied as starch. The intake of cholesterol was about $200 \mathrm{mg} /$ day in each subject.
The ileostomy contents were collected during 96 hours. The ileostomy bags were changed every two hours during the day until 2300 and at 0700 . The bags were sealed and immediately frozen. The ileostomy bags were freeze dried separately, and their contents then mixed and combined for each 24 hour period; these pooled samples were then stored at $-20^{\circ} \mathrm{C}$ until analysis.

Blood samples and duodenal bile were obtained on the two following days after an overnight fast. Gall bladder contraction was stimulated by intravenous cholecystokinin injection, and $5 \mathrm{ml}$ of dark concentrated gall bladder bile was usually obtained. Any dilute bile was discarded. The bile was collected and immediately transported to the laboratory for analysis.

\section{ANALYSIS OF ILEOSTOMY CONTENTS}

From the thoroughly mixed, and finely ground freeze dried ileostomy contents, a $5 \mathrm{mg}$ sample was added to an extraction tube and fixed amounts of deuterium labelled cholic and chenodeoxycholic acid were added as internal standards. The samples were hydrolysed with $1 \mathrm{M}$ potassium hydroxide in closed steel tubes for 16 hours at $110^{\circ} \mathrm{C}$. The alkaline solution was extracted three times with diethyl ether to remove most of the neutral steroids. The bile acids were then extracted from the acidified water phase with ethyl ether, methylated with diazomethane, and converted into trimethylsilyl ether derivatives. The derivatives were analysed by gas chromatography-mass spectrometry, essentially as described earlier. ${ }^{1617}$ The coefficient of variation from duplicate determinations was $<5 \%$ for both cholic and chenodeoxycholic acid.

For analysis of cholesterol, deuterium labelled cholesterol was added as internal standard. The samples were then hydrolysed with $1 \mathrm{M}$ potassium hydroxide in methanol for 30 hours at $60^{\circ} \mathrm{C}$ and then extracted with hexane. The derivatives were analysed by gas chromatography-mass spectrometry, essentially as described earlier ${ }^{18}$ with later modification. ${ }^{19}$ The coefficient of variation from duplicate determinations was $<5 \%$.

\section{ANALYSIS OF BILIARY LIPIDS AND BILE ACID COMPOSITION}

For the determination of cholesterol and phospholipids, a portion of the duodenal content was immediately extracted with 20 volumes of chloroform-methanol, 2:1 ( $\mathrm{vol} / \mathrm{vol})$. Cholesterol was determined by an enzymatic method, ${ }^{20}$ and phospholipids by the method of Rouser et al. ${ }^{21}$ The total bile acid concentration in one aliquot of the bile sample was determined using a $3 \alpha$-hydroxysteroid dehydrogenase assay. ${ }^{22}$ The comparative concentrations of cholesterol, bile acids, and phospholipids were expressed as molar percentages of total biliary lipids. The cholesterol saturation was calculated according to Carey, ${ }^{23}$ assuming a total lipid content of $10 \mathrm{~g} / \mathrm{dl}$. Bile acid composition was determined by gas-liquid chromatography. ${ }^{24}$ 
TABLE II Excretion of bile acids and cholesterol in ileostomy effluent and serum concentrations of lathosterol and $7 \alpha$-hydroxycholesterol before and after exlusion of distal ileum

\begin{tabular}{llll}
\hline & Ileum intact & $\begin{array}{l}\text { Distal ileum } \\
\text { excluded }\end{array}$ & $\begin{array}{l}\text { Significance } \\
\text { of difference }\end{array}$ \\
\hline Cholic acid (mg/day) & $440(60)$ & $2120(280)$ & $\mathrm{p}<0 \cdot 005$ \\
Chenodeoxycholic acid (mg/day) & $230(30)$ & $1080(120)$ & $\mathrm{p}<0.005$ \\
Cholesterol (mg/day) & $940(130)$ & $930(130)$ & $\mathrm{NS}$ \\
S-Lathosterol $(\mu \mathrm{g} / \mathrm{ml})$ & $1 \cdot 1(0 \cdot 3)$ & $7 \cdot 0(2 \cdot 1)$ & $\mathrm{p}<0.005$ \\
S-7 $\alpha$-hydroxycholesterol $(\mathrm{ng} / \mathrm{ml})$ & $20(5)$ & $105(40)$ & $\mathrm{p}<0.005$ \\
\hline
\end{tabular}

Results shown as mean (SEM).

\section{SERUM LIPIDS}

Plasma cholesterol and triglycerides were assayed by enzymatic methods (Boehringer Mannhiem, Mannheim, Germany). Lipoproteins were analysed by a combination of ultracentrifugation and precipitation. 2526 In brief, plasma was spun at $35000 \mathrm{rpm}$ for 18 hours at $4^{\circ} \mathrm{C}$ in a Contron Centrikon Y-2060 ultracentrifuge equipped with a 45.6 rotor. The tubes were sliced, and the supernatant fraction as well as the infranatant were analysed for cholesterol and triglyceride content. A portion of the infranatant was treated with phosphotungstic acid to precipitate proteins containing apolipoprotein $\mathbf{B}$ and was analysed as described above. For the analyses of apolipoproteins AI and B, immunoturbidometric methods were used (Behringwerke, Marburg, Germany). Serum concentrations of $7 \alpha$-hydroxycholesterol, lathosterol, and free cholesterol were determined by isotope dilution-mass spectrometry as described previously. ${ }^{11} 13$

\section{STATISTICAL ANALYSIS}

Data are given as mean (SEM). The significance of differences was evaluated with Wilcoxon's signed rank test.

\section{Results}

The ileal excretion of cholic and chenodeoxycholic acid was 440 (60) $\mathrm{mg} /$ day and 230 (30) $\mathrm{mg} /$ day respectively and increased four to five

TABLE III Biliary lipid composition before and after exclusion of distal ileum

\begin{tabular}{lccc}
\hline & Ileum intact & $\begin{array}{l}\text { Distal ileum } \\
\text { excluded }\end{array}$ & $\begin{array}{l}\text { Significance } \\
\text { of difference }\end{array}$ \\
\hline Cholesterol (molar \%) & $5 \cdot 9(0 \cdot 5)$ & $5 \cdot 1(0 \cdot 5)$ & NS \\
Bile acids (molar \%) & $71 \cdot 0(1 \cdot 6)$ & $71 \cdot 6(1 \cdot 9)$ & NS \\
Phospholipids (molar \%) & $23 \cdot 1(1 \cdot 2)$ & $23(1 \cdot 7)$ & NS \\
Cholesterol saturation (\%) & $80(6)$ & $71(19)$ & NS \\
Cholic acid (\%) & $65 \cdot 2(2 \cdot 6)$ & $66 \cdot 4(3 \cdot 2)$ & NS \\
Chendeoxycholic acid (\%) & $34 \cdot 4(2 \cdot 7)$ & $33 \cdot 7(3 \cdot 2)$ & NS \\
\hline
\end{tabular}

Results shown as mean (SEM).

TABLE IV Plasma lipid composition before and after exclusion of distal ileum

\begin{tabular}{|c|c|c|c|}
\hline & Ileum intact & $\begin{array}{l}\text { Distal ileum } \\
\text { excluded }\end{array}$ & $\begin{array}{l}\text { Significance } \\
\text { of difference }\end{array}$ \\
\hline S-Cholesterol (mmol/1) & $4.8(0.4)$ & $3 \cdot 5(0 \cdot 2)$ & $\mathrm{p}<0.005$ \\
\hline $\mathrm{S}$-Triglycerides $(\mathrm{mmol} / \mathrm{l})$ & $1 \cdot 2(0 \cdot 2)$ & $1.6(0.3)$ & $\mathrm{p}<0.005$ \\
\hline LDL Cholesterol (mmol/l) & $3.0(0.4)$ & $1 \cdot 7(0 \cdot 2)$ & $\mathrm{p}<0.01$ \\
\hline HDL Cholesterol (mmol/i) & $1 \cdot 4(0 \cdot 1)$ & $1 \cdot 3(0 \cdot 1)$ & NS \\
\hline VLDL Cholesterol (mmol/1) & $0.1(0.0)$ & $0.5(0.1)$ & NS \\
\hline VLDL Triglycerides (mmol//) & $0.7(0.2)$ & $1.1(0.2)$ & $\mathrm{p}<0.01$ \\
\hline Apolipoprotein A $(\mathrm{g} / \mathrm{l})$ & $1 \cdot 7(0 \cdot 1)$ & $1 \cdot 7(0 \cdot 1)$ & NS \\
\hline Apolipoprotein B (g/l) & $1 \cdot 2(0 \cdot 1)$ & $0.9(0.1)$ & $\mathrm{p}<0.005$ \\
\hline
\end{tabular}

Data shown as mean (SEM). times when distal ileum was excluded (Table II). The ratio of cholic/chenodeoxycholic acid in the ileal effluent was 1.9 and was not changed by distal ileum exclusion. Cholesterol excretion was 940 (130) $\mathrm{mg} /$ day with ileum intact and was not changed by exclusion (Table II). Only traces of bile acids other than cholic and chenodeoxycholic acids and neutral steroids other than cholesterol were found in the ileostomy content.

In duodenal bile, cholesterol, bile acid, and phospholipid concentrations were $5.9(0.5)$ molar\%, 71.0 (1.6) molar\%, and $23 \cdot 1(1 \cdot 2)$ molar\%, respectively, in patients with intact ileum, and there was no significant change when distal ileum was excluded (Table III). Cholesterol saturation of the duodenal bile showed a slight but not significant decrease (Table III). There was also no significant change in bile acid composition; cholic acid averaging $65 \cdot 2(2 \cdot 6) \%$ and chenodeoxycholic acid $34.4(2 \cdot 7) \%$, ratio cholic/chenodeoxycholic acid $2 \cdot 1(0 \cdot 2)$, in patients with intact ileum (Table III). Very small amounts of lithocholic acid were found in one and ursodeoxycholic acid in three patients with intact ileum but not in any patient with distal ileum excluded.

Plasma concentrations of total cholesterol, LDL cholesterol, and apolipoprotein B decreased significantly, whereas plasma concentrations of total triglycerides and VLDL triglycerides increased significantly (Table IV). LDL triglycerides, HDL cholesterol, HDL triglycerides, VLDL cholesterol, and apolipoprotein AI were not significantly changed (Table IV).

The serum concentrations of lathosterol and the ratio of lathosterol to free cholesterol as well as serum $7 \alpha$-hydroxycholesterol were increased several fold in patients with distal ileum excluded (Table II).

The body weight of the patients was not significantly changed after ileal exclusion (Table I).

\section{Discussion}

This study confirms that exclusion of terminal ileum causes malabsorption of bile acids. ${ }^{34}$ The excretion of both cholic and chenodeoxycholic acid increased four to five times in the ileostomy content after ileum exclusion.

It may seem surprising that the malabsorption of bile acids was not associated with an increased excretion of cholesterol from the ileostomy in our patients. Most of the cholesterol is, however, absorbed in the upper part of the intestine and the concentration of bile salts there may be sufficient for the absorption. Our results are in accordance with those of Färkkilä et $a l^{5}$ who showed that not only the distal ileum but also part of the proximal part of the small intestine must be resected before a significant malabsorption of cholesterol occurs. Buchwald et al ${ }^{27}$ showed that hyperlipidemic patients subjected to removal of 200 $\mathrm{cm}$ of the distal bowel had a malabsorption of both bile acids and cholesterol. Grundy $\mathrm{et} \mathrm{al}^{3}$ studied four patients with resection of terminal 
ileum. Only two of these patients had a slight malabsorption of cholesterol.

It may be argued that the enhanced utilisation of cholesterol in bile acid synthesis may decrease the biliary output of cholesterol and thus there could be a malabsorption of cholesterol despite the unchanged excretion of cholesterol from the ileostomy. The findings that the concentration of cholesterol and the cholesterol saturation in duodenal bile was unchanged do not support this hypothesis, although the possibility cannot be completely excluded that the malabsorption of bile acids may lead to a decreased biliary secretion of bile acids and thus equal the decreased cholesterol output. In agreement with our finding Färkkilä et $a l^{5}$ showed that patients with resection of only distal ileum had a normal fractional cholesterol absorption. In further support for a normal absorption of cholesterol, Carrella et $a l^{28}$ showed that patients treated with cholestyramine, who also should have a selective malabsorption of bile acids, have an unchanged biliary secretion of cholesterol as well as unchanged biliary lipid composition.

Our model makes it possible to draw important conclusions with respect to the regulatory role of bile acids for cholesterol homeostasis. To some extent the situation should be similar to that occurring in patients treated with cholestyramine. Cholestyramine has, however, a greater affinity for dihydroxy bile acids than trihydroxy bile acids, leading to a higher degree of malabsorption of chenodeoxycholic acid and deoxycholic acid than cholic acid. Because cholic acid is almost exclusively absorbed in the distal part of the ileum whereas chenodeoxycholic acid is also absorbed by passive uptake in the upper part of the intestine, ${ }^{29} 30$ ileum exclusion could be expected to lead to a higher loss of cholic acid than chenodeoxycholic acid. In our patients there was, however, a similar loss of both cholic acid and chenodeoxycholic acid in the ileostomy content after the ileal exclusion. The ratio between the two bile acids in the ileostomy content was unchanged. A possible explanation could be that an ileal exclusion leads to an increase in the glycine to taurine ratio. ${ }^{31}$ As a consequence more cholic acid is conjugated to glycine, which might lead to a higher absorption of cholic acid by passive uptake. ${ }^{1}$ It is also possible that the small intestine may adapt to an exclusion and increase the absorption of bile acids in the remaining part of the small intestine.

As could have been expected the malabsorption of bile acids led to a compensatory increase in bile acid biosynthesis. This could be shown not only by measuring the excreted amounts of bile acids in the ileostomy content but also by measuring the serum concentration of $7 \alpha$-hydroxycholesterol. We have previously shown that there is a high correlation between circulating concentrations of $7 \alpha$-hydroxycholesterol and the activity of the rate limiting enzyme in bile acid biosynthesis, the cholesterol $7 \alpha$-hydroxylase. ${ }^{13}$ In accordance with this, the increase in serum concentration of 7 $\alpha$-hydroxycholesterol and increase in bile acid excretion was about the same after the ileal exclusion.

Despite the fact that there was no apparent malabsorption of cholesterol, the rate of synthesis of cholesterol increased after ileum exclusion. Thus we could show that the serum concentrations of lathosterol increased more than sixfold. We have previously shown that there is a high degree of correlation between the serum concentration of lathosterol and the activity of the hepatic HMG CoA reductase in human liver. ${ }^{12}$

These results are in accordance with the opinion that bile acids may regulate the activity of the hepatic HMG CoA reductase by a mechanism independent of the effect of bile acids on the cholesterol absorption. This is in good agreement with recent work with different animal models in our laboratory. ${ }^{32}$ Thus we showed that cholestyramine treatment increased cholesterol synthesis in lymph fistulated rats. In the second situation the effect of cholestyramine on HMG CoA reductase activity must be mediated by the flux of bile acids as there is no transport of cholesterol from the intestine to the liver. The mechanism by which the bile acids affect HMG CoA reductase is still unknown. The bile acids may either suppress HMG CoA reductase directly, or their effect on the enzyme may be mediated by effects on cholesterol $7 \alpha$-hydroxylase. We have speculated that the activity of the last enzyme may be of importance for a small pool of cholesterol that is possibly the direct regulator of HMG CoA reductase. ${ }^{32}$

An increased demand for cholesterol can be expected to lead to reduced concentrations of circulating cholesterol resulting from an increased uptake in the liver through increased LDL receptor activity. In accordance with this we found a decrease in serum total cholesterol, in particular LDL cholesterol. As a consequence of this also apolipoprotein $\mathbf{B}$ was decreased. It has been reported that ileum resection may lead to an increase in HDL cholesterol. ${ }^{33} 34$ No such increase could be found in our study, however.

Cholestyramine treatment and other conditions leading to increased synthesis of both cholesterol and bile acids are known to cause an increase in serum total triglycerides, mainly because of an increase in the VLDL fraction. ${ }^{35}$ As could have been expected the ileal exclusion led to a significant increase in both total triglycerides and VLDL triglycerides. It has been shown that this increase is caused by increased synthesis. ${ }^{35}$ The mechanism behind this increase is not known. The possibility has been discussed that the increased secretion of VLDL is a consequence of the increased cholesterol synthesis, with a common pool for bile acid synthesis and VLDL secretion. Another explanation could be the direct stimulation of phospholipid and triglyceride synthesis sharing early steps in their biosynthesis. ${ }^{36}$

Malabsorption of bile acids has been associated with an increased risk of gall stones. ${ }^{8}$ The pathogenic mechanism has been 
suggested to be cholesterol supersaturation in bile resulting from an increased loss of bile acids in faeces. ${ }^{937}$ In agreement with some recent studies ${ }^{3839}$ we could not find, however, any changes in composition of duodenal bile after the ileal exclusion. In a recent study it was shown that there is an increased risk for development of gall stones after abdominal surgery. ${ }^{40}$ As most of the patients with bile acid malabsorption have had at least one major abdominal operation this might be the explanation for the association between malabsorption and development of gall stones.

To summarise, exclusion of about $95 \mathrm{~cm}$ of the ileum leads to an apparent selective malabsorption of bile acids. The malabsorption of bile acids leads to a condition similar to that occurring after cholestyramine treatment with increased synthesis of both cholesterol and bile acids and decreased concentrations of circulating cholesterol. The results show the important role of the bile acid flux for cholesterol homeostasis.

This paper is dedicated to Professor Dr G Paumgartner in honour of his 60 th birthday.

The skilful technical assistance of Ms Gunvor Alvelius, Ms Danuta Cosliani, Mr Manfred Held, Ms Ingela Svensson, and Ms Anita Lövgren is gratefully acknowledged. This study was supported by grants from the Swedish Medical Research Council (project 03X-04793 and 03x-3141), the Swedish Society of Medicine, and the Karolinska Institute.

1 Carey MC. The enterohepatic circulation. In: Arias IM Jakoby WB, Popper H, Schachter D, Shafritz DA, eds. The liver: biology and pathobiology. New York: Raven Press, 1988: 573-616.

2 Hofmann AF. The enterohepatic circulation of bile acids in man. In: Schultz SG, ed. Handbook of physiology. man. In: Schultz SG, ed. Handbook of physiology.

3 Grundy SM, Ahrens EH Jr, Salen G. Interruption of the enterohepatic circulation of bile acids in man: comparaenterohepatic circulation of bile acids in man: comparative effects of cholestyramine and ileal exclusion on

cholesterol metabolism. F Lab Clin Med 1971; 78: 94-121.
Heaton KW. Disturbances of bile acid metabolism in intestinal disease. Clin Gastroenterol 1977; 6: 69-89.

5 Färkkilä MA, Tilvis RS, Miettinen TA. Cholesterol absorption regulates cholesterol metabolism and plasma lipoprotein levels in patients with gut exclusion. Gastroenterology 1988; 94: 582-9.

6 Borgström B, Barrowman JA, Lindström M. Roles of bile acids in intestinal lipid digestion and absorption. In Danielsson $\mathrm{H}$, Sjövall $\mathrm{J}$ eds. New comprehensive biochemistry. Amsterdam: Elsevier Scientific Publishing, 1985: 405-25.

7 Åkerlund J-E, Reihnér E, Angelin B, Rudling M, Ewerth S, Björkhem I, et al. Hepatic metabolism of cholesterol in Björkhem I, et al. Hepatic metabolism of cholesterol in Crohn's disease: effect of partial
Gastroenterology 1991; 100: 1046-53.

8 Heaton KW, Read AE. Gall stones in patients with disorders of the terminal ileum and disturbed bile salt metabolism. $B M F$ 1969; 3: 494-6.

9 Dowling RH, Bell GD, White J. Lithogenic bile in patients with ileal dysfunction. Gut 1972; 13: 415-20.

10 Buchwald H, Varco RL, Matts JP, Long JM, Fitch LL Campbell GS, et al. Effect of partial ileal bypass surgery on mortality and morbidity from coronary heart disease in patients with hypercholesterolemia. $N$ Engl f Med 1990; 323: $946-55$.

11 Lund E, Sisfontes L, Reihnér E, Björkhem I. Determination of serum levels of unesterified lathosterol by isotope
dilution-mass spectrometry. Scand f Clin Lab Invest 1989; 49: $165-71$.

12 Björkhem I, Miettinen T, Reihnér E, Ewerth S, Angelin B Einarsson K. Correlation between serum levels of some cholesterol precursors and activity of HMG-CoA reductase in human liver. $\mathcal{F}$ Lipid Res 1987; 28: 1137-43.

13 Björkhem I, Reihnér E, Angelin B, Ewerth S, Åkerlund J-E Einarsson $\mathrm{K}$. On the possible use of the serum level of 7 alpha-hydroxycholesterol as a marker for increased activity of the cholesterol 7 alpha-hydroxylase in humans. f Lipid Res 1987; 28: 889-94.

14 Björkhem I, Kallner A. Hepatic 7 alpha-hydroxylation of cholesterol in ascorbate-deficient and ascorbatesupplemented guinea pigs. F Lipid Res 1976; 17: 360-5.

15 Angelin B, Björkhem I, Einarsson K. Individual serum bile acid concentrations in normo- and hyperlipoproteinemia as determined by mass fragmentography: relation to bile acid pool size. F Lipid Res 1978; 19: 527-37.

16 Angelin B, Björkhem I, Einarsson K, Ewerth S. Hepatic uptake of bile acids in man. Fasting and postprandial concentrations of individual bile acids in portal venous concentrations of individual bile acids in portal venous

17 Ewerth S, Angelin B, Einarsson K, Nilsell K, Björkhem I. Serum concentrations of ursodeoxycholic acid in portal Serum concentrations of ursodeoxycholic acid in portal
venous and systemic venous blood of fasting humans as determined by isotope dilution-mass spectrometry. Gastroenterology 1985; 88: 126-33.

18 Björkhem I, Blomstrand R, Svensson L. Serum cholesterol determination by mass fragmentography. Clin Chim Acta 1974; 54: 185-93.

19 Schaffer R, Sniegoski L, Welch MJ, White E, Cohen A, Hertz HS, et al. Comparison of two isotope dilution mass spectrometric methods for determination of total serum cholesterol. Clin Chem 1982; 28: 5-8.

20 Roda A, Festa D, Sama C, Mazzella G, Aldini R, Roda E, et al. Enzymatic determination of cholesterol in bile. Clin al. Enzymatic determination

21 Rouser G, Fleischu S, Yamamota A. Two dimensional thin-layer chromatography separation of polar lipid and determinations of phospholipids by phosphorous analysis of spots. Lipids 1970; 5: 494-6.

22 Fausa $\mathrm{O}$, Skålhegg $\mathrm{B}$. Quantitative determination of bile acids and their conjugates using thin-layer chromatography and purified 3 alpha-hydroxysteroid dehydrogenase. Scand F Gastroenterol 1974; 9: 249-54.

23 Carey $M$. Critical tables for calculating the cholesterol saturation of native bile. $\mathcal{f}$ Lipid Res 1978; 19: 945-55.

24 Angelin B, Einarsson K, Leijd B. Biliary lipid composition during treatment with different hypolipidaemic drugs. Eur during treatment with different

25 Carlson K. Lipoprotein fractionation. F Clin Pathol 1977: 26 (suppl 5): 32-7.

26 Lopes-Virella M, Stone P, Ellis S, Colwell J. Cholesterol determination in high-density lipoproteins separated by three different methods. Clin Chem 1977; 23: 882-4.

27 Buchwald H, Moore P, Varco R. Surgical treatment of hyperlipedemia. Circulation 1974; 49 (suppl 1): 1-37.

28 Carrella M, Ericsson S, Del Piano C, Angelin B, Einarsson $\mathrm{K}$. Effect of cholestyramine treatment on biliary lipid secretion rates in normolipidaemic men. $\mathcal{F}$ Intern Med 1991; 229: 241-6.

29 Krag E, Phillips SF. Active and passive bile acid absorption in man. Perfusion studies of the ileum and jejunum. $\mathcal{F}$ Clin in man. Perfusion studies

30 Angelin B, Einarsson K, Hellström K. Evidence for the absorption of bile acids in the proximal small intestine of normo and hyperlipidemic subjects. Gut 1976; 17: 420-5.

31 Garbutt JT, Heaton KW, Lack L, Tyor MP. Increased ratio of glycine- to taurine-conjugated bile salts in patients with ileal disorders. Gastroenterology 1969; 56: 711-20.

32 Åkerlund J-E, Björkhem I. Studies on the regulation of cholesterol 7 alpha-hydroxylase and HMG-CoA reductase in rat liver: effects of lymphatic drainage and ligation of the lymph duct. $\mathcal{F}$ Lipid Res 1990; 31: 2159-66.

33 Koivisto PV, Miettinen TA. Effect of ileal exclusion on kinetics of very low density lipoprotein triglycerides in familial hypercholesterolemia. Clin Chim Acta 1986; 161: 91-101.

34 Campos CT, Matts JP, Fitch LL, Speech JC, Long JM, Buchwald H. Lipid results of partial ileal bypass in patients with heterozygous, type II-A hyperlipoproteinemia. Program on the surgical control of the hyperlipidemias. Surgery 1990; 108: 601-10.

35 Angelin B, Leijd B, Hultcrantz R, Einarsson K. Increased turnover of very low density lipoprotein triglyceride during treatment with cholestyramine in familial hypercholesterolaemia. f Intern Med 1990; 227: 201-6.

36 Angelin B, Einarsson K. Bile acids and lipoprotein metabolism. Atheroscler Rev 1986; 15: 41-66.

37 Rutgeerts P, Ghoos Y, Vantrappen G. Effects of partial ileocolectomy and Crohn's disease on biliary lipid secrelieocolectomy and Crohn's disease

38 Wise L, Stein T. The effect of jejunoileal bypass on bile composition and formation of biliary calculi. Ann Surg composition and

39 Färkkilä MA. Biliary cholesterol and lithogeneity of bile in patients after ileal resection. Surgery 1988; 104: 18-25. 40 Little J, Avramovic J. Gallstone formation after major abdominal surgery. Lancet 1991; 337: 1135-7. 